Abstracta Iranica Abstranica

Revue bibliographique pour le domaine irano-aryen

Volume 42-43 | 2021

Comptes rendus des publications de 2019-2020

\title{
Pierfrancesco Callieri. “A Fountain of Sasanian Age from Ardashir Khwarrah"
}

Alessia Zubani

\section{OpenEdition}

1 Journals

Édition électronique

URL : https://journals.openedition.org/abstractairanica/52813

DOI : $10.4000 /$ abstractairanica. 52813

ISSN : 1961-960X

\section{Éditeur :}

CNRS (UMR 7528 Mondes iraniens et indiens), Éditions de l'IFRI

\section{Référence électronique}

Alessia Zubani, «Pierfrancesco Callieri. "A Fountain of Sasanian Age from Ardashir Khwarrah" ", Abstracta Iranica [En ligne], Volume 42-43 | 2021, document 26, mis en ligne le 30 juillet 2021, consulté le 12 décembre 2022. URL : http://journals.openedition.org/abstractairanica/52813 ; DOI : https:// doi.org/10.4000/abstractairanica.52813

Ce document a été généré automatiquement le 12 décembre 2022.

Tous droits réservés 


\title{
Pierfrancesco Callieri. “A Fountain of Sasanian Age from Ardashir Khwarrah"
}

\author{
Alessia Zubani
}

\section{RÉFÉRENCE}

Pierfrancesco Callieri. “A Fountain of Sasanian Age from Ardashir Khwarrah", With a Note on the Archaeometric Investigations by Maria Letizia Amadori, in Y. Moradi (ed.), with the assistance of S. Cantan, E. J. Keall and R. Boroujeni. Afarin Nameh. Essays on the Archaeology of Iran in Honour of Mehdi Rahbar. Tehran: The Research Institute of Cultural Heritage and Tourism (RICHT), 2019, p. 93-100.

1 En 1993-1994, un grand bassin en calcaire avec des décorations en relief a été découvert sur le site d'Ardashir Khwarrah, dans la région du Fārs (aujourd'hui conservé dans la base ICHHTO de Firuzabad). Son état actuel, ainsi que l'impossibilité de le comparer avec d'autres objets similaires, ne permettent pas d'indiquer avec certitude sa fonction. Menant une étude approfondie sur cet objet, l'A. fait l'hypothèse qu'il faisait partie d'une fontaine monumentale, datée de l'époque sassanide. Si tel est le cas, il s'agirait du tout premier témoignage d'une fontaine monumentale. Une étude archéométrique par Maria Letizia Amadori complète l'article, en apportant des détails sur la caractérisation de la pierre du bassin. 


\section{AUTEURS}

ALESSIA ZUBANI

Labex HaStec, EPHE 